\title{
CONTEXTO SOCIOAMBIENTAL DO PARQUE ESTADUAL DO SUMIDOURO, APA CARSTE DE LAGOA SANTA, MG ${ }^{1}$
}

\author{
Lucas de Lima Fernandes $\operatorname{Padoan}^{2}$ \\ Leonardo Vasconcelos de Souza ${ }^{2}$
}

\section{Resumo}

Conflitos entre unidades de conservação e comunidades de seu entorno são comuns devido à divergência de seus interesses de uso e apropriação do ambiente natural. A partir do contexto da APA Carste de Lagoa Santa, Minas Gerais, buscou-se compreender a dinâmica espacial do Parque Estadual do Sumidouro e sua relação com a comunidade local de Quinta do Sumidouro. Essa relação foi levantada através de análise comparativa entre as ações de conservação realizadas pelo Parque e a percepção da comunidade sobre essa gestão. A insatisfação da população demonstrou que a interação entre os interesses de conservação e as dinâmicas sociais ainda é ineficaz nos processos de gestão de ambientes naturais.

Palavras chave: Parque Estadual do Sumidouro; conflitos socioambientais; percepção socioambiental.

\begin{abstract}
Conflicts between protected areas and communities are common due to the divergence of their interests in the use and appropriation of the natural environment. From the context of the APA Carste de Lagoa Santa, Minas Gerais, sought to understand the spatial dynamics of that Parque Estadual do Sumidouro and its relationship with the local community of the Quinta do Sumidouro. This ratio was raised by a comparative analysis between the conservation actions undertaken by the Park and the community's perception of this management. The dissatisfaction of the population demonstrated that the interaction between conservation interests and the social dynamics is still ineffective in the management processes of natural environments.
\end{abstract}

Keywords: State Park of Sumidouro; social and environmental conflicts; social and environmental awareness.

\section{Introdução}

A Área de Proteção Ambiental (APA) Carste de Lagoa Santa está localizada no vetor norte da Região Metropolitana de Belo Horizonte (RMBH), Minas Gerais, abrangendo os municípios de Confins, Funilândia, Lagoa Santa, Matozinhos e Pedro Leopoldo (Figura 01). Foi instituída por meio do Decreto Federal No 98.881 de 25 de janeiro de 1990 e, de acordo com o Instituto Chico Mendes de Conservação da Biodiversidade (ICMBio), atualmente delimita uma área de cerca de 39.000 hectares dentro do bioma Cerrado.

\footnotetext{
${ }^{1}$ Artigo organizado a partir dos trabalhos para a disciplina "Aulas Práticas Integradas de Campo - A" cursada no segundo semestre de 2012.

${ }^{2}$ Alunos do curso de graduação em Ciências Socioambientais pela Universidade Federal de Minas Gerais. E-mail: lpadoan2@hotmail.com e leodesouza.90@hotmail.com
} 


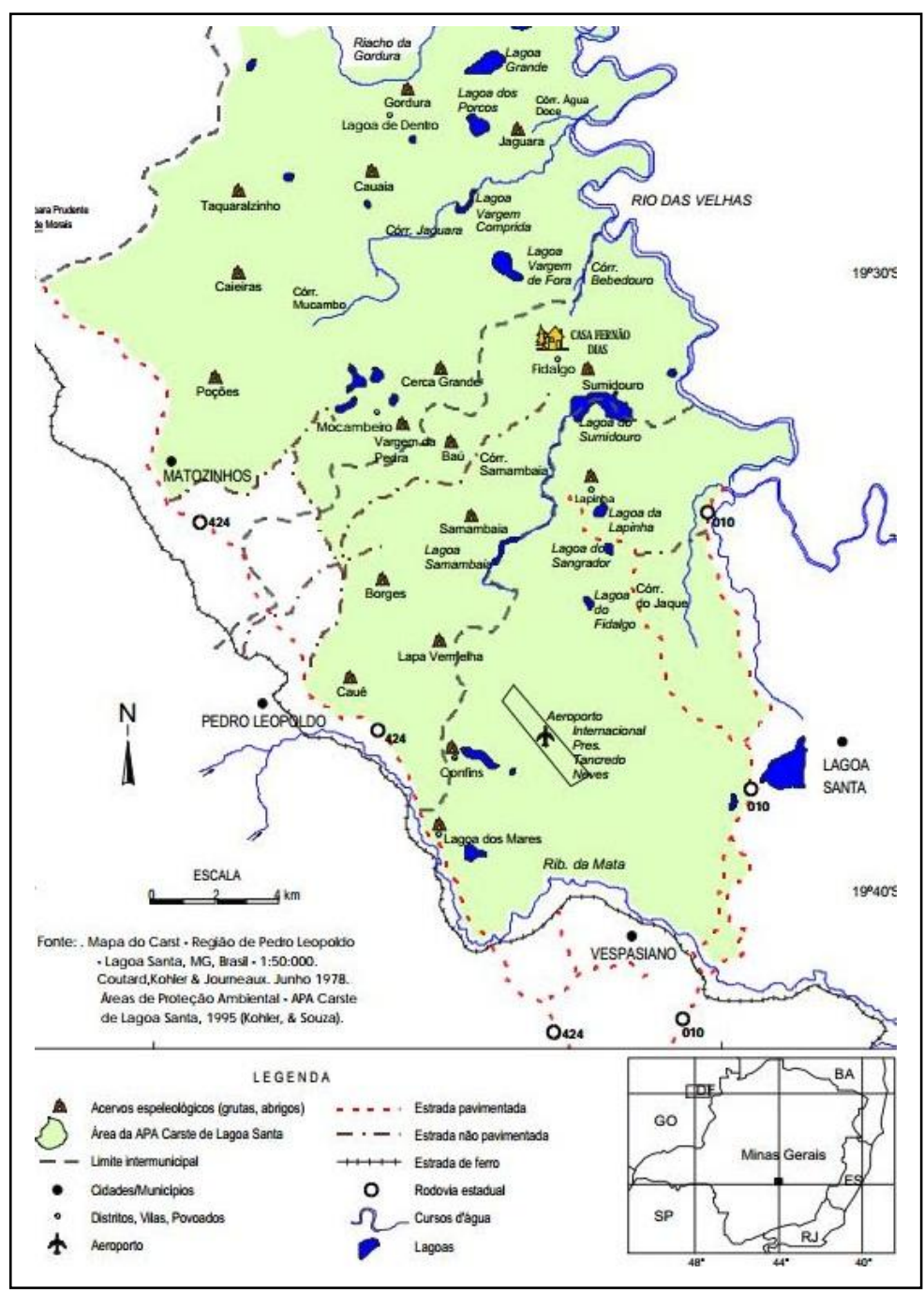

Figura 01: Caracterização da APA Carste de Lagoa Santa. FONTE: Gestão Ambiental: APA Carste de Lagoa Santa. Belo Horizonte: IBAMA / CPRM / GERIDE, 1998.

Estudos do Instituto Brasileiro do Meio Ambiente e dos Recursos Naturais Renováveis (IBAMA) (1998a) indicaram que a APA Carste de Lagoa Santa possui cerca de 600 espécies vegetais de importância biológica muito alta, 216 espécies de aves de importância biológica extrema e 42 espécies de mamíferos de importância biológica especial. $\mathrm{O}$ estudo também identificou sítios arqueológicos de grande relevância histórico-cultural na região, tendo sido contabilizadas 523 grutas com registros arqueológicos pré-históricos, sendo uma delas o local onde foi encontrado o fóssil "Luzia", cuja datação indica se tratar do hominídeo mais antigo das Américas.

Devido à extensa área da APA, este trabalho foi limitado à região do entorno do Parque Estadual (PE) do Sumidouro, Unidade de Conservação (UC) de Proteção Integral criada pelo 
governo do estado de Minas Gerais através do Decreto Estadual No 20.375 de 4 de Janeiro de 1980 cujos 1.300 hectares são geridos pelo Instituto Estadual de Florestas de Minas Gerais (IEF).

O solo do Parque é constituído por rochas calcárias que formam um relevo cárstico de baixa resistência à ação de dissolução química da água. Esse desgaste contínuo ocorre há milhões de anos e atualmente pode ser observado através das surgências e dos sumidouros que se formaram na região, locais onde ocorre a drenagem de água formando córregos subterrâneos e lagoas com regime de cheias sazonal que secam periodicamente em função da oscilação do nível subterrâneo do aquífero cárstico. A lagoa mais conhecida da região é a Lagoa do Sumidouro, ou simplesmente, Sumidouro (Figura 02) que inclusive empresta seu nome ao Parque.

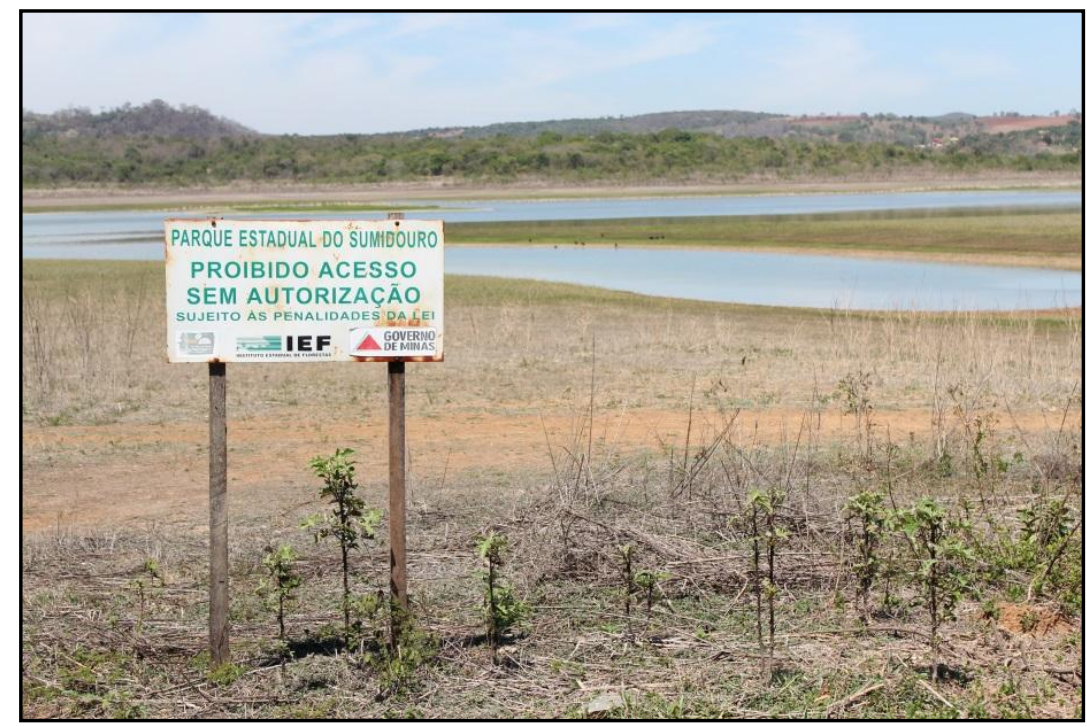

Figura 02: Lagoa do Sumidouro, Minas Gerais. Foto: Lucas Gabriel de Oliveira Gonçalves, 2012.

A Lagoa do Sumidouro faz parte do conjunto de lagoas cársticas da região que possuem importância ecológica expressiva, o que possibilitou com que a APA passe atualmente por um processo de análise com a finalidade de se tornar um "Sítio Ramsar", conforme anunciado por José Eugênio Cortes, membro do Conselho Consultivo ${ }^{3}$ da APA, na revista ICMBio em Foco, de 20 de julho de 2012. A Convenção de Áreas Úmidas, ou simplesmente Convenção Ramsar, foi formada em 1971 e constitui um acordo intergovernamental para que seus países signatários mantenham o compromisso de preservar áreas úmidas de importância global, já que tais ambientes constituem importantes habitats para muitas espécies animais e vegetais. Dois dos motivos que influenciam a região de ser cotada como um Sítio Ramsar é (i) sua quantidade de espécies endêmicas e (ii) o alto fluxo de aves aquáticas migratórias encontradas na Lagoa do Sumidouro.

\footnotetext{
${ }^{3}$ O Conselho Consultivo é um órgão colegiado que integra a estrutura administrativa da APA e visa assegurar a participação social em sua gestão.
} 
Essas e outras medidas que possam promover a conservação do Carste de Lagoa Santa se fazem necessárias uma vez que a região recebe cada vez mais influências dos grandes centros urbanos de seu entorno. A expansão urbana ocorre no vetor norte da RMBH desde a década de 1970, com a revitalização e abertura de comércios e indústrias próximos à região do Carste de Lagoa Santa, como a construção do Aeroporto Internacional Tancredo Neves. Atividades mineradoras também são comuns na área da APA e o setor industrial apresenta grande relevância para a região, sendo impulsionado pela grande disponibilidade de matéria prima, embora, segundo o Plano de Manejo da APA, a atividade agropecuária seja a base de sua economia.

Em meados dos anos 1980, a expansão habitacional do vetor norte da RMBH se deu de maneira mais acelerada quando condomínios de luxo e loteamentos se fizeram cada vez mais presentes. A atual expansão urbana da região demonstra que a tendência de crescimento populacional é maior no conjunto metropolitano do que em Belo Horizonte, o que justifica a necessidade de estudos e avaliações a respeito da região observada.

A rica geodiversidade, a expressiva biodiversidade e todo o patrimônio arqueológico, espeleológico, histórico e cultural da região constituíram em importantes fatores utilizados pelo IBAMA (1998a) para justificar a criação da APA com o objetivo de conservar as dinâmicas e os elementos que compõe a área cárstica de Lagoa Santa.

Apesar da inegável importância ecológica da APA Carste, é preciso considerar as populações humanas que habitam e convivem na região, bem como as diferentes percepções que seus diferentes grupos sociais possuem acerca desse ambiente. A partir dessa problemática, este trabalho é apresentado como uma pequena contribuição para ampliar os estudos acadêmicos transdisciplinares sobre a região Carste de Lagoa Santa. Seus objetivos são (i) analisar alguns fatores ambientais relacionados com a qualidade ambiental da região e (ii) avaliar a percepção da comunidade de Quinta do Sumidouro sobre os objetivos e práticas de conservação do PE do Sumidouro.

Essas informações foram utilizadas para compor um diagnóstico do contexto da APA Carste de Lagoa Santa, discutindo-se os possíveis impactos socioambientais percebíveis na área. A análise proposta permite a conciliação entre os interesses de uso e apropriação dos espaços pelas comunidades locais e os interesses de conservação do ambiente natural das UCs, buscando uma dinâmica espacial onde população e ambiente não sejam impossibilitados de coexistir, ressaltando que o homem também é parte da natureza.

\section{Material e métodos}

A pesquisa foi realizada utilizando diversos métodos que proporcionaram uma abordagem multidisciplinar do contexto do Parque Estadual do Sumidouro. O trabalho na Lagoa do Sumidouro envolveu (i) a análise da paisagem, baseada em protocolo desenvolvido pelo WWF (2007), (ii) a observação e identificação de aves aquáticas e organismos bentônicos, (iii) a análise de qualidade da água e (iv) uma pesquisa semiestruturada com a comunidade da Quinta do Sumidouro. 


\section{Resultados}

\section{a) Diversidade de Habitats e Criticidade da APA}

Utilizando uma adaptação do Protocolo de Avaliação Rápida da Diversidade de Habitats e análise de criticidade dos parâmetros/impactos elaborado pelo WWF (2007), foram identificados parâmetros potencialmente prejudiciais para as dinâmicas ambientais do entorno da Lagoa do Sumidouro aos quais foram atribuídos valores e pontuações de modo que fossem posteriormente comparados e analisados de forma mais eficaz.

Foi observado que os tipos de ocupação das margens do Sumidouro são predominantemente por residências e vegetação natural, sendo presentes campos de pastagens e ocupação por agricultura longe da mata preservada do Parque (Figura 03). Não foram notadas erosões próximas às margens da Lagoa apesar da cobertura vegetal do solo ser escassa.

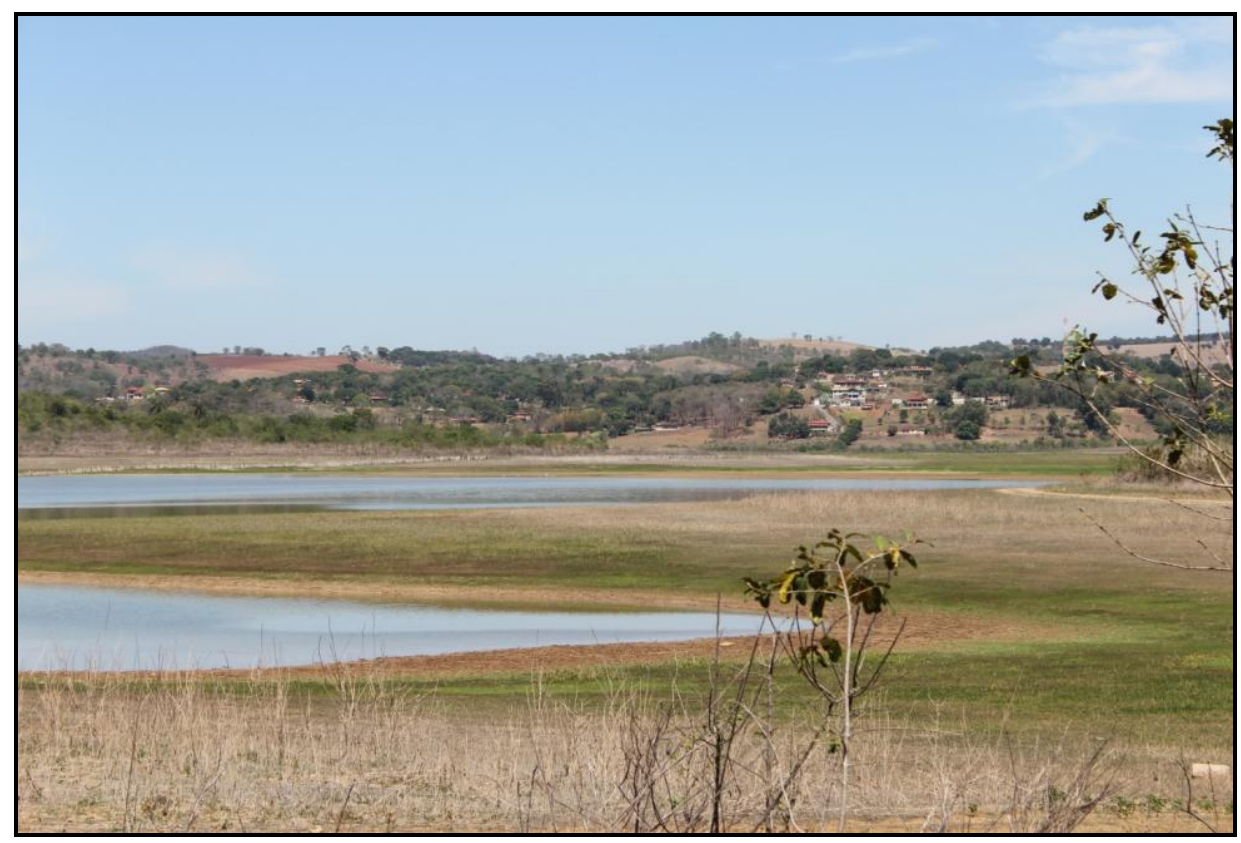

Figura 03: Contraste entre o ambiente natural do PE do Sumidouro e a ocupação residencial. Foto: Lucas Gabriel de Oliveira Gonçalves, 2012.

A análise dos resultados (Quadro I) permite concluir que a ocupação residencial apresenta maior capacidade de interferência nas dinâmicas naturais da área, seguida pelo desmatamento recente, sendo possível enquadrar todas essas atividades no contexto da expansão urbana do vetor norte da RMBH. Não se pode desconsiderar que todas as formas de uso por estarem ocorrendo simultaneamente, acabam por pressionar os processos biológicos que ocorrem no Parque e em seu entorno. 
Quadro I. Resultado da análise de criticidade e avaliação rápida da Lagoa do Sumidouro.

\begin{tabular}{|c|c|c|c|c|}
\hline \multirow{2}{*}{ Impacto } & \multicolumn{4}{|c|}{ Criticidade } \\
\cline { 2 - 5 } & Extensão & Severidade & Permanência & Total \\
\hline Ocupação residencial & 4 & 4 & 4 & 64 \\
\hline Desmatamento recente & 3 & 3 & 3 & 27 \\
\hline Pesca & 2 & 3 & 3 & 18 \\
\hline Agricultura & 2 & 2 & 2 & 8 \\
\hline Pastagem & 1 & 1 & 1 & 1 \\
\hline Presença de estradas & 1 & 1 & 1 & 1 \\
\hline
\end{tabular}

\section{b) Aves aquáticas}

Rodrigues e Michelin (2005) verificaram que as dinâmicas de aves migratórias podem ser utilizadas para se obter indicadores de qualidade ambiental e da água, o que ressalta a importância de se estudar esses animais e suas dinâmicas no Sumidouro para promover a efetiva conservação da região do Parque. A partir de dois pontos em margens opostas da Lagoa do Sumidouro foram observadas e identificadas espécies de aves aquáticas ali presentes. A identificação foi realizada através de catálogo próprio elaborado com base nos dados da $10^{a}$ Lista de Aves do Brasil do Comitê Brasileiro de Registros Ornitológicos ${ }^{4}$.

A maioria das aves observadas estava a uma distância média de 15 metros dos observadores, o que dificultou avistar de forma precisa suas características, mesmo utilizando-se binóculos. Das 36 espécies listadas no catálogo, foram identificadas apenas oito, o que, a princípio sugere uma baixa riqueza de aves aquáticas. Contudo, conforme orientado por Frederic Mendes Hughes (doutorando em Ecologia e Conservação pela Universidade Federal de Minas Gerais) esses dados podem indicar a necessidade de se ampliar o número de dias de observação dos animais e também alternar horários e épocas do ano, pois estes são fatores que interferem na ocorrência dos indivíduos. As espécies observadas e sua abundância estão apresentadas no Quadro II.

Quadro II. Abundância de aves observadas na Lagoa do Sumidouro.

\begin{tabular}{|c|c|c|}
\hline Espécies & Indivíduos (n) & Abundância (\%) \\
\hline Podilymbus podiceps (Mergulhão) & 63 & 43,2 \\
\hline Phalacrocorax brasilianus (Biguá) & 43 & 29,5 \\
\hline Egretta thula (Garça Branca) & 12 & 8,2 \\
\hline Dendrocygna autumnalis (Marreca Cabocla) & 11 & 7,5 \\
\hline Vanellus chilensis (Quero-Quero) & 6 & 4,1 \\
\hline Syrigma sibilatrix (Maria Faceira) & 6 & 4,1 \\
\hline Himantopus mexicanus (Pernilongo de costas negras) & 4 & 2,7 \\
\hline Pandion haliaetus (Águia Pescadora) & 1 & 0,7 \\
\hline Total & $\mathbf{1 4 6}$ & $\mathbf{1 0 0}$ \\
\hline
\end{tabular}

\footnotetext{
${ }^{4}$ Disponível em: <http://www.cbro.org.br/CBRO/listabr.htm>.
} 
Segundo o Laboratório de Tecnologia Educacional da Universidade Estadual de Campinas (UNICAMP) ${ }^{5}$, as oito espécies observadas possuem hábitos alimentares parecidos, alimentando-se principalmente de larvas, insetos, girinos, peixes e gramíneas. Possuem uma semelhança clara em relação à preferência por locais abertos como pastos e lagoas. Preferencialmente escolhem locais próximos à água para fazer seus ninhos, como em árvores baixas e no solo.

Tendo em vista essas semelhanças é notável a importância da Lagoa do Sumidouro para essas espécies, uma vez que o local possui diversos recursos fundamentais para a manutenção de suas dinâmicas ecológicas, como, por exemplo, fonte de água e alimento (Figura 04), locais seguros para reprodução e refúgio de predadores.

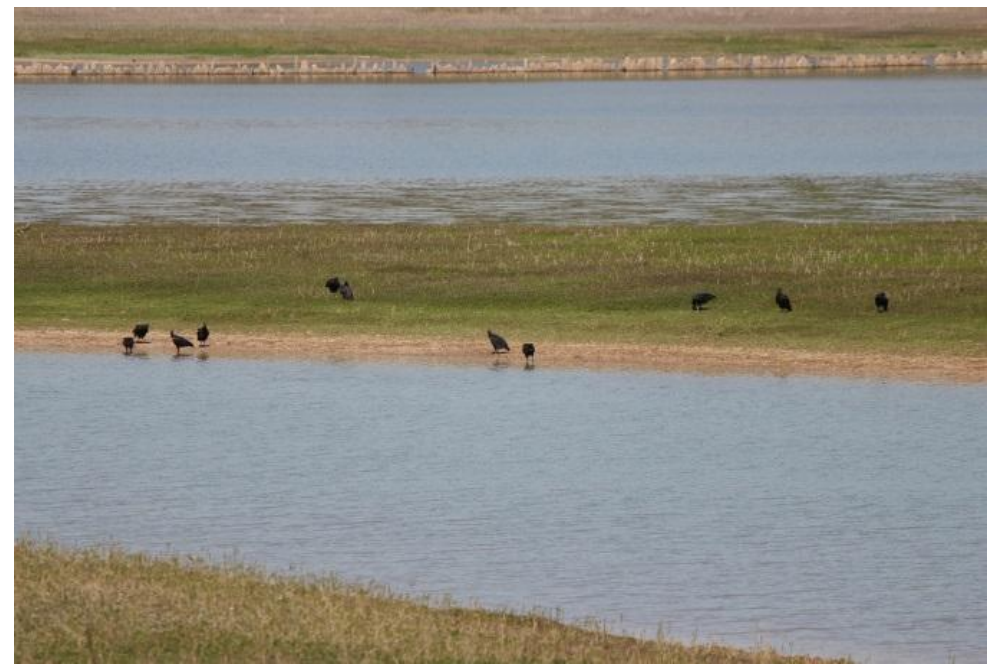

Figura 04. Bando de Biguás observado na Lagoa do Sumidouro. Foto: Lucas Gabriel de Oliveira Gonçalves, 2012.

\section{c) Organismos bentônicos}

Dornfeld (2002) estudou os substratos inferiores de ambientes aquáticos (a parcela de sedimentos que se aglomera próxima ou ao fundo de rios, lagos e mares) e também constatou a existência de organismos bioindicadores. Isso se deve ao fato desses sedimentos se constituírem em verdadeiros ecossistemas para organismos bentônicos (ou bentos), seres macroinvertebrados de grande influência na transformação de matéria orgânica, entre outras funções ecológicas. Os bentos também foram objeto de estudo para Queiroz, Trivinho-Strixino e Nascimento (2000) que os classificaram como importantes, tanto para a estrutura como para funcionamento dos sistemas aquáticos e, por fim, verificaram como sua distribuição dentro do ecossistema é influenciada por fatores tais como profundidade e vegetação do substrato, dentre outros. A análise desses bioindicadores é útil para se compreender alterações nas dinâmicas de ambientes aquáticos.

\footnotetext{
${ }^{5}$ Disponível em: <http://www.lte.ib.unicamp.br>.
} 
A coleta de substrato foi realizada em dois pontos da Lagoa para posterior identificação de organismos bentônicos. O material foi analisado em laboratório onde houve uma seleção das espécies encontradas e a contagem de seus indivíduos. A identificação dos organismos bentônicos foi realizada através do Atlas de Identificação Rápida dos Principais Grupos de Macroinvertebrados Bentônicos adaptado por Marcelo da Silva Moretti (2004) a partir do Guia para el estúdio de los macroinvertebrados acuáticos del Departamento de Antioquio de Pérez (1988).

A análise dos grupos bentônicos da Lagoa também resultou em um valor baixo da riqueza, já que só foram identificados três grupos de indivíduos entre os 14 listados no Atlas. A abundância desses seres também é bastante reduzida, sendo que mais de $99 \%$ dos bentos identificados foi de um mesmo grupo. Foram identificados 372 indivíduos da classe Gastropoda subdivididos em dois morfotipos diferentes, além da presença de uma pupa e de um Oligochaeta. Esses resultados também podem estar relacionados ao reduzido número de coletas e de áreas amostrais.

\section{d) Análise da água da Lagoa do Sumidouro}

Amostras de água do Sumidouro foram analisadas no local através do Ecokit para análise de água da Alfakit. O kit traz um conjunto de reagentes (não identificados pela empresa) e um manual que pode ser facilmente seguido para se obter diversos parâmetros sobre a qualidade de determinada amostra de água. Os testes realizados analisaram o pH, a dureza e a concentração de ortofosfato, amônia e oxigênio dissolvidos na água.

Os testes dos parâmetros da água do Sumidouro indicaram (i) a baixa concentração de íons $\mathrm{H}^{+}$dissolvidos na água ( $\mathrm{pH}=7,5$ ); (ii) a baixa concentração de nutrientes dissolvidos na água [0mg.L. $\left.\left(\mathrm{PO}_{4}\right)^{-1}\right]$ o que, segundo o Universo Ambiental, pode indicar a ausência de eutrofização ou de lançamento de efluentes sanitários no curso d'água; (iii) uma saturação de oxigênio de 9mg.L $\left(\mathrm{O}_{2}\right)^{-1}$, que, de acordo com orientações recebidas em sala de aula, aproxima-se da concentração de saturação ideal de 9,2mg.L $\left(\mathrm{O}_{2}\right)^{-1}$ ao nível do mar para uma temperatura de $20^{\circ} \mathrm{C}$; (iv) uma concentração de $160 \mathrm{mg}\left(\mathrm{L} \cdot \mathrm{CaCO}_{3}\right)^{-1}$ de cátions metálicos dissolvidos na água, o que indica uma água relativamente dura, ou seja, com nível elevado de metais pesados dissolvidos; e (v) a concentração de amônia de $0,1214 \mathrm{mgL}\left(\mathrm{N}_{-} \mathrm{NH}_{3}\right)^{-1}$, o que indica que a água não é tóxica, já que, segundo debates em classe, a toxicidade acontece quando este valor se aproxima de $2,3 \mathrm{mgL}(\mathrm{N}$ $\left.\mathrm{NH}_{3}\right)^{-1}$. Apesar de o Ecokit ser uma ferramenta confiável para análises físico-químicas de água, testes mais precisos podem ser realizados através do uso de sondas, com medições dentro do próprio ambiente aquático.

\section{e) Contexto e percepções da comunidade de Quinta do Sumidouro}

O roteiro de entrevista utilizado para captar as percepções da comunidade de Quinta do Sumidouro contém 131 perguntas que abrangem temas como (i) uso da casa e histórico da família no local, (ii) percepção sobre mudanças da paisagem, (iii) conhecimento sobre Unidades de Conservação, (iv) conhecimento sobre grutas, cavernas e pinturas rupestres da região, (v) conhecimento sobre aves aquáticas da região, (vi) abastecimento de água do domicílio, (vii) sistemas de 
esgotamento sanitário, (viii) resíduos sólidos, (ix) saúde, (x) associativismo e (xi) conhecimento sobre alguns órgãos públicos. As entrevistas foram realizadas com cerca de 40 famílias escolhidas de forma aleatória, entre população residente no distrito e sitiantes.

No geral, embora a maioria das famílias seja antiga na comunidade, nenhuma efetua práticas de agricultura ou criação de animais em seu quintal. As famílias são compostas em média por 3,6 pessoas, a maioria adultos e crianças, sendo baixa a concentração de jovens, que migram por falta de oportunidades de emprego ou por preferirem viver próximo aos centros urbanos.

A população entrevistada, em sua maioria, atribui o fato da região estar mais bonita e preservada por conta da implantação da UC, sendo facilmente percebido o aumento do número de diferentes espécies animais e vegetais, o que demonstra assim a importância da conservação da área.

Como aspecto positivo de se morar na região, a tranquilidade foi ressaltada por todos os entrevistados, embora muitos tenham manifestado sua insatisfação com os turistas que vêm comprometendo essa tranquilidade e contribuindo para o aumento da insegurança. Os moradores também atribuem aos turistas o descarte de resíduos sólidos urbanos em determinados pontos da APA. Os locais mais comuns para o acúmulo desse lixo eram as lagoas cujo acesso ainda é livre e atraem alguns banhistas para a região. $\mathrm{O}$ descarte de entulho em bota-foras clandestinos ainda é ação frequente na região, que encontra seu mercado imobiliário altamente valorizado. Os resíduos da construção civil podem causar o entupimento dos sumidouros, como já foi constado pelo IEF, e também contribuírem para a contaminação do meio físico, principalmente a água.

O IEF/MG realiza ações de limpeza periódicas nos locais com acúmulo de resíduos além de ter iniciado campanhas de conscientização realizadas através de placas educativas como uma medida para contornar tal situação. Esse trabalho é de fundamental importância uma vez que o lançamento de resíduos sólidos nesses locais afeta diretamente as dinâmicas ecológicas e os próprios moradores da região, colaborando na propagação de vetores de doenças como ratos, baratas, mosquitos, entre outros, além de causar danos diretos ao ambiente e a biodiversidade da região.

O contato com a comunidade mostrou que a população é a favor das ações de conservação ambiental propostas pela gestão do Parque do Sumidouro, contudo demonstra insatisfações com a proibição do livre acesso à sua área. Antes da criação do parque, a população usufruía da área para pescar, retirar lenha ou simplesmente como área para lazer. Muitas são as queixas das comunidades em relação à proibição de uso do local, já que muitos de seus costumes e práticas estão relacionados à área do Parque. Alguns moradores relatam seu sentimento de frustração e angústia quando pensam que não podem mais ir aos locais onde brincavam durante sua infância e tiveram outras inúmeras experiências e recordações. $\mathrm{O}$ valor que essas pessoas dão a esses locais não está sendo assegurado no processo de gestão do ambiente natural, uma vez que é necessário que as mesmas paguem para poder entrar em local que uma vez já lhes foi de livre acesso. 
Os moradores questionaram a falta de informações e esclarecimentos mais precisos sobre as permissões e restrições da UC. Muitos dos entrevistados não sabem qual é a função do IEF e alegam que não foram consultados no processo de criação do PE do Sumidouro. Os moradores da comunidade afirmaram que foram informados sobre algumas normas referentes ao Parque somente após sua criação, mas tais informações ainda não lhes são tão claras. A comunidade enxerga tais dúvidas como limitantes à função de preservação das UCs, pois, caso eles soubessem mais sobre a dinâmica do parque e como podem utilizar os espaços de conservação, poderiam ajudar a manter o patrimônio natural e ainda usufruírem do ambiente como lhes era de costume.

A comunidade se sente prejudicada com a chegada da UC, porém reconhece a necessidade de preservar o local. Em contrapartida, ela não entende a necessidade de tantas restrições que lhe são impostas e, pelo simbolismo que a área lhe exerce, defende que até poderiam se tornar aliados dos órgãos gestores em busca da conservação do espaço e ao mesmo tempo desfrutá-lo. Ou seja, a identidade local compartilhada pela comunidade que relaciona sua vivência à existência da Lagoa e de seu entorno, pode ser acionada conjuntamente em prol da preservação do PE do Sumidouro garantindo sua perpetuação.

\section{Conclusões}

O PE do Sumidouro é mais um exemplo de conflitos socioambientais entre gestores de Unidades de Conservação e comunidades de seu entorno, cenário que é cada vez mais visto no Brasil. Esse tipo de conflito ocorre quando gestores públicos tentam corrigir questões pontuais como a degradação ambiental sem analisar o contexto geral da localidade de atuação. Em grande parte das situações, as UCs são propostas com base apenas em estudos biológicos sobre dinâmicas ecológicas que ressaltam a perspectiva mais preservacionista que defende o isolamento entre meio natural e ser humano.

Os dados sobre a biota e a paisagem analisados neste trabalho proporcionaram verificar que a região, apesar de sofrer diversos impactos ambientais negativos, está em um estágio de conservação promissor. Porém, a insatisfação da população também deve ser considerada antes de se afirmar que a UC está sendo eficaz em seus objetivos de proteção ambiental, uma vez que a população humana também deve estar incluída no conceito espacial de ambiente. A insatisfação da população demonstrou que a interação entre os interesses de conservação e os interesses sociais ainda não é verificada de forma eficaz nos processos de gestão de ambientes naturais. Também foi verificada a insatisfação da população quanto às imposições da gestão do PE do Sumidouro, o que torna relevante a necessidade promoção da preservação ambiental levando-se em conta as opiniões e percepções da população de seu entorno.

Uma estratégia para reduzir os conflitos socioambientais verificados no PE do Sumidouro é a realização de reuniões periódicas entre a comunidade e os gestores da área protegida. Essas reuniões corrigiriam o problema da falta de comunicação e esclareceriam as dúvidas existentes entre os moradores. Os encontros poderiam acontecer com certa periodicidade em locais, como 
escolas, na associação de moradores e até mesmo dentro do Parque, para que os moradores interessados saibam quais medidas estão sendo tomadas no ambiente em que vivem. O local, as datas e os horários devem ser acordados entre os representantes da UC e a população, de modo que se possa atrair o maior contingente possível da população sem prejudicar o trabalho dos funcionários dos órgãos de gestão ambiental.

O que este trabalho demonstra é que somente a criação da APA não foi suficiente para deter as ações prejudiciais à biodiversidade e à população da região cárstica de Lagoa Santa, já que suas diretrizes não são seguidas de forma efetiva. O contato com os moradores locais foi essencial para a compreensão de como a população interage com a UC. Tal compreensão é de suma importância para análises transdisciplinares e permite discutir as reais ameaças, sociais e ambientais, presentes em determinada localidade.

Tendo em vista o processo de pesquisa e análise referentes ao estudo realizado no Parque do Sumidouro, sabe-se que ainda são necessários estudos mais aprofundados sobre a realidade socioambiental da região. Estudos anteriores sobre análise da qualidade da água da Lagoa do Sumidouro e a consideração da importância ecológica e arqueológica da área corroboram para as iniciativas de preservação de toda a região. Da mesma maneira, os impactos dos projetos de expansão do vetor norte da RMBH também se mostram relevantes no momento de elaboração de novas ações que auxiliem na resolução ou mesmo mitigação de tais danos socioambientais.

\section{Bibliografia}

BERBERT-BORN, M. Carste de Lagoa Santa, MG: Berço da paleontologia e da espeleologia brasileira. In: SCHOBBENHAUS, C. et al. (Ed.). Sítios Geológicos e Paleontológicos do Brasil. 2002.

CMP. Conservation MeasuresPartnerships. Disponível em:

<http://www.conservationmeasures.org/initiatives/standards-for-project-management $>$. Acesso em: 05 maio 2012.

DORNFELD, C. B. Utilização de análises limnológicas, bioensaios de toxicidade e macroinvertebrados bentônicos para o diagnóstico ambiental do reservatório de Salto Grande (Americana, SP). Dissertação (Mestrado em Ciências da Engenharia Ambiental)- Escola de Engenharia de São Carlos, Universidade de São Paulo, São Carlos, 2002.

GIAU. Página eletrônica do Guia Interativo de Aves Urbanas. Disponível em: <http://www.giau.ib.unicamp.br/giau/index.php>. Acesso em: 9 dez. 2012.

IBAMA. Gestão Ambiental: APA Carste de Lagoa Santa. Belo Horizonte: IBAMA / CPRM / GERIDE, 1998a. 1998b. . Sócio-Economia, APA Carste de Lagoa Santa. Belo Horizonte: IBAMA/CPRM, A. L. SILVEIRA, I. C. B.; L. MOURA (Eds.) ICMBio em Foco, v. 204, 20 jul. 2012.

ICMBio. Instituto de Chico Mendes de Conservação da Biodiversidade. Disponível em: $<$ http://www.icmbio.gov.br/portal/biodiversidade/unidades-de-conservacao/biomas- 
brasileiros/cerrado/unidades-de-conservacao-cerrado/2057-apa-do-carste-de-lagoa-santa.html> . Acesso em: 31 jan. 2013.

IEF. Instituto Estadual de Florestas de Minas Gerais. Disponível em:

<http://www.ief.mg.gov.br/areas-protegidas/215?task=view>. Acesso em: 4 dez. 2012.

KREBS, C. J. Ecological methodology, 2. ed. USA: Addison Wesley Longman, 1999.

Ministério das Minas e Energia. Programa Geologia do Brasil: Levantamento da Geodiversidade. Belo Horizonte, 2010.

MORETTI, M. S. Atlas de Identificação Rápida dos Principais Grupos de Macroinvertebrados Bentônicos. Belo Horizonte, 2004.

QUEIROZ, J. F.; TRIVINHO-STRIXINO, S.; NASCIMENTO, V. C. Organismos bentônicos bioindicadores da qualidade das águas da Bacia do Médio São Francisco. Brasília: Ministério da Agricultura e do Abastecimento, 2000.

PADOAN, L. L. F. et al. Relatório Integrador: Aulas Práticas Integradas de Campo A. Trabalho da Disciplina de Aulas Práticas Integradas de Campo A, Universidade Federal de Minas Gerais, Belo Horizonte, 2013.

RAMSAR. Convenção Ramsar de Áreas úmidas. Disponível em:

<http://www.ramsar.org/cda/en/ramsar-about-about-ramsar/main/ramsar/136\%5E7687_4000_0_>. Acesso em: 31 jan. 2013.

RODRIGUES, M.; MICHELIN, V. B. Riqueza e diversidade de aves aquáticas de uma lagoa natural no sudeste do Brasil. Revista Brasileira de Zoologia, p. 928-935, 2005.

SÃO PAULO. Fundação para a Conservação e a Produção Florestal do Estado de São Paulo: Fundação Florestal. Disponível em: 〈http://www.fflorestal.sp.gov.br/missao.php>. Acesso em: 05 fev. 2013.

UNIVERSO AMBIENTAL. Controle de qualidade da água. Disponível em:

<http://www.universoambiental.com.br/Arquivos/Agua/ProcessosQuimicosdeTratamentodeEflue ntes08.pdf>. Acesso em: 14 dez. 2012.

WWF. Padrões de Gestão de Projeto e Programa de Conservação do WWF. Versão: 09 fev. 2007. Disponível em:

<http://assets.panda.org/downloads/wwf_standards_overview_portuguese nov_1_2010.pdf>. Acesso em : 4 dez. 2013. 